\title{
Simulating the Effects of Risk Occurrences on a Hazardous Material Transportation Model
}

\author{
Vasiliki Kazantzi ${ }^{1 *}$, Nikolas Kazantzis ${ }^{2}$, Vassilis C. Gerogiannis ${ }^{1}$ \\ ${ }^{1}$ Department of Project Management, Technological Education Institute of Larissa, Greece ${ }^{2}$ Department of Chemical \\ Engineering, Worcester Polytechnic Institute, Worcester, MA, USA \\ ${ }^{1}$ kazantzi@teilar.gr, 2nikolas@wpi.edu, 1'gerogian@teilar.gr
}

\begin{abstract}
The present paper explores the effects of different risk incidents on a Transportation Model developed for HazMat (Hazardous Materials) shipments. The particular objective of this study is to elucidate the effects of occurrence probabilities of the different risk events on the transportation model featuring total transportation cost. First, the present research study addresses the problem of identifying and evaluating various risk factors that influence the HazMat transportation network. Next, a modeling framework for HazMat transportation is proposed as a special case of the traditional transportation network in the presence of risk-informed safety constraints that need to be satisfied. A comprehensive characterization of the underlying risk profile that is probabilistically realized through appropriately conducted Monte Carlo simulations that capture the effect of underlying irreducible uncertainties associated with the main risk-drivers is followed by the proposed solution approach to the corresponding minimum cost flow network problem while reducing risks at the desired levels. In order to examine the impact of the occurrence possibilities of different risk events on the transportation model, appropriate parameterized simulation work is carried out, resulting in identifying release probability zones and safe network configurations that correspond to certain low-risk levels and degrees of risk-related uncertainties. These simulation studies help making informed decisions on optimal transportation configurations for ensuring safety in hazardous material shipments. Finally, the presented methodological framework demonstrates its potential usefulness in making risk-informed decisions while transporting goods and classes of materials that can be potentially proven dangerous to public health and ecosystem functions.
\end{abstract}

Keywords: transportation, hazardous material, risk analysis, simulation

\section{Introduction}

The problem of identifying potential risks and their consequences in Hazardous Material (HazMat) transportation has been a great concern and largely acknowledged by many researchers, government bodies, regulatory authorities and the public in general as one of the main issues in the broader field of transportation security (List et al., 1991). Transportation itself entails a degree of risk since it involves a number of goods movements. For instance, in the case of a gasoline truck involved in an accident on a highway, there is a probability of a major fire which can even threaten the lives of drivers and members of the population around the area. In addition, if the truck carries a flammable liquefied gas, such as propane, then the consequences of the accident would be much worse and more serious for the population residing near the accident site.

There is a significant number of HazMat that global society needs to transport via highways, railroads, waterways and pipelines and that has to take place in the safest way possible. This kind of materials can be extremely harmful to the environment and to human health, and although this 
situation corresponds to a low probability - but high consequence - transportation risk event, the attendant risk level needs to be assessed and characterized even in the absence of sufficient data for the quantification of all parameters involved.

There are two main difficulties in assessing the risk; one can observe that probabilities of incident occurrences in HazMat transportation are very low and reported incident data are very scarce (Erkut and Gzara, 2008). This lack of consistent and sufficient data and the difficulty of obtaining accurate parameter values lead to high degrees of uncertainties associated with incident rates and consequence measurements for dangerous goods transportation. There are many critical variables that need to be taken into account in assessing the actual risk in Hazmat transportations (material type, mode of transportation, container type, meteorological and weather conditions, geographical location, season, time of the day, road conditions), as well as variables that depend on the human component and management of the transportation process (such as age, training and condition of the driver, management system, operations performed, equipment used etc). Based on a huge number of possible HazMat transportation alternative combinations, one can conclude that this is a very case-dependent problem, and it is debatable whether accurate and unbiased assessments of the risk involved in such situations can be performed for any kind of instances in HazMat transportation.

However, one can use a number of experiments to look into how risk-related parameters can be incorporated in a real transportation model and how these parameters affect the whole transportation system. In this regard, the use of simulation in exploring the effects of risk occurrences on a transportation model is suggested to help obtain insights and improve security in accommodating HazMat shipments. The use of simulation has also been acknowledged by many researchers. A review of previous research related to HazMat transportation risk assessment is next presented, followed by some background concepts and the description of the methodology used in this work to develop the HazMat transportation model. The model features both cost and risk associated with flows of the HazMat commodity vehicles and seeks to minimize cost in the context of an acceptable degree of risk.
The results from the proposed transportation model and corresponding analysis regarding how risk uncertainties evolve and affect the model are presented in the last section of this paper, whereas conclusions for this study are drawn based on the specific modeled situation.

\section{Prior Research}

The particular transportation problem considered in the present paper has been previously studied on many levels. There is a double-centered arena of HazMat transportation problems; one considered with optimal transportation routing and the other with risk probabilities evaluation of HazMat transportation. A review of relevant issues can be found in Barnhart and Laporte (2007).

In analyzing various aspects of the transportation network problem, List et al. (1991) provided a literature review on risk analysis, routing and facility location methodologies, pointing out that there is a number of conflicting variables in this analysis that are casespecific for the transportation network. The optimal route planning problem is recognized as a multiobjective problem in nature, since there are inherently conflicting objectives; there are cases where low-riskroutes lead to more expensive transportation costs because of their possible larger length. Thus, many authors have formulated multi-objective transportation models. McCord and Leu (1995) generated a biobjective problem using the multi attribute utility theory, transforming the problem into a single-objective one and using the shortest-path algorithm to determine the optimum path. Many other researchers formulated multiobjective models; integer programming models (Erkut and Gzara, 2008, Kara and Verter, 2004, Zografos and Androutsopoulos, 2008) within different context orientations, and solved those using appropriate heuristic algorithms (Ziliaskopoulos and Wardell, 2000).

As for the second area of interest in HazMat transportation, there is a number of papers that have pointed out the uncertainties and pitfalls in assessing accident and release rates as well as characterizing consequential risk incidents because of the significant gap in available data. Harwood et al (1993) described a general procedure in estimating truck accident rates as a function of road and area type (urban/rural) from state data on highway geometrics, traffic volume, and 
accidents. Release probabilities in accidents were also derived by using combined federal and state truck accident data. However, the study also underlined some issues in combining data from different states, where estimates relate to different local factors that may need to be used as parameters in this kind of models. A more inclusive, fuzzy-oriented work has been presented in Qiao, Gentile and Mannan (2005), where multiple parameters are integrated with accident frequency probabilities. A different approach to HazMat transportation risk analysis was undertaken recently by Clark and Besterfield-Sacre, (2009), where critical variables are identified and related consequences (dollar loss and release quantity) were measured through exploratory data modeling based on US HazMat incident data, aiming at ultimately developing an empirical Bayesian network model for data-driven decision making. The analysis showed that the strongest relationships among all influential variables affecting HazMat transportation risk are the material type and container type, season and material type, as well as shift and location. Finally, a valuable and alternative way of estimating probability HazMat release incidents is the use of fault tree and event tree analysis methods, as in the study of Pet-Armacost et al (1999), in which a transportation risk analysis of Hydrazine was conducted to determine whether or not a relief valve was needed. The analysis was performed using combined event and fault tree techniques, in conjunction with Monte Carlo simulation, which offered a thorough examination of the impact of different input variables on risk occurrences.

The present work addresses the HazMat transportation problem by identifying uncertainties in input variables and risk assessment, while propagating those to explore their effects on transportation network configuration. Monte Carlo simulation seem to provide a simple, yet comprehensive and useful tool to obtain some insightful information on risk behavior of the targeted transportation system.

\section{Background}

The most common risk function in HazMat transportation is the so-called "traditional risk model", defined by equation (1):
$R=\sum_{i=1} P_{i} * C s_{i}$

where $P_{i}$ is the probability of a release event (or incident) on link $i$ of a specific path of an ordered set of links $\{1,2, \ldots, \mathrm{n}\}$ and $C s_{i}$ is a measure of the consequence of a release event on link $i$, which can be expressed as the number of people been affected (living) within a specific distance (e.g. $1 \mathrm{~km}$ ) from the incident site (Erkut and Ingolfsson, 2005). The model is also consistent with the definition used in the U.S. Department of Transportation (1989) guidelines for transporting HazMat and represents the expected value of the consequence of a HazMat truck traveling along the specific path. It is noted here that each single link $i$ is assumed to be homogeneous in the probability of a release event, as well as the population density.

Moreover, in estimating the probability of a release incident on a link $i$, the corresponding accident rate, conditional release probability given an accident and the link's length are incorporated in the following equation (Erkut and Verter, 1998):

$P_{i}=A R_{i}^{*} P_{i}(R L \mid A) * d_{i}$

where $A R_{i}$ is the accident rate (probability) on link $i$ (per Vehicle-Kilometer - VKm), $P(R L \% A)$ is the conditional release probability given an accident on link $i$ and $d_{i}$ the length of link $i$. Also, $C s_{i}$ in (1) can be calculated as follows:

$C s_{i}=P d_{i} * \pi * r_{i}^{2}$

where $P d_{i}$ is the population density in the neighborhood (an impact area of radius $r_{i}$ ) of the link (in persons per $\mathrm{Km}^{2}$ ).

A generic framework for risk evaluation can be formulated in three stages (Barnhart and Laporte, 2007):

- evaluation of the probability of an undesirable event (for example, an incident with a release of a harmful material)

- determination of potential exposure level of the population and the environment, given the nature of the event 
- estimation of the magnitude of the consequences (e.g. deaths, injured people, damages) given the exposure level.

In fact, each of these stages of the process produces one or more probability distributions. In the next section, the pertinent research methodology for the proposed model is described based on the aforementioned process.

\section{Research Methodology}

The estimated value of risk may be considered either in an absolute sense, or as a quantitative comparative representation between different alternatives for risk screening and classification risk purposes or finally as a means to compare different solutions assuming in an analyzed road network various routes linking two set points and assessing the value of risk for each. An examination of several risk factors needs to be clearly carried out first. The most influential HazMat factors identified in literature are material type, mode of transportation, container type, meteorological and weather conditions, geographical location, season, time of the day, road conditions, management of the transportation, age, training and condition of the driver, operations performed, and equipment used (Clark and Besterfield-Sacre, 2009). However, there is always a number of dominant and risk-inclusive factors that may exhibit major effects on risk measurements. In every single case, critical variables may need to be hierarchically evaluated based on expert judgments and possibly available data. A more comprehensive study for data exploration and analysis methods is therefore recommended in order to elucidate the effects of certain critical factors on various HazMat handling cases.

In this work we focus on acci-dent-related incidents for highway transportation, since transporta-tion-related risk for materials such as flammable liquids is dominated by highway incidents. First, we consider truck accident rates that depend on several factors, such as truck type, configuration and size, geographic location, time of the day, road and environmental conditions and so on. Most available data refer to urban and rural roads and are expressed in terms of the number of accidents per Million Vehicle-Kilometers traveled (MVKm). Hamouda (2004) reported different truck
Table 1. Truck accident rates by highway type for different countries (per MVKm)

\begin{tabular}{|l|c|c|c|c|r|}
\hline $\begin{array}{c}\text { Highway } \\
\text { Type }\end{array}$ & California & $\begin{array}{c}\text { Nether- } \\
\text { lands }\end{array}$ & France & Norway & Greece \\
\hline Urban & 0.99 & 0.492 & 0.973 & 1.431 & 0.98 \\
Rural & 0.33 & 0.164 & 0.324 & 0.477 & 0.3263 \\
Arterials & 1.548 & 0.768 & 1.522 & 2.238 & 1.5288 \\
\hline
\end{tabular}

accident rates for different countries (US, Netherlands, France and Norway). Using these data and the Operational Program in Transport Country Report for Greece (Directorate General XVI, 2000), the following values are considered for accident rates in different countries (Table 1).

One can observe that the ratios for the accident rates between urban and rural roads are constant and consistent for all countries considered (accident rates in rural roads are one-third of the corresponding accident rates in urban areas, whereas accident rates in arterials are more than 1.5 times of the corresponding accident rates in urban areas). As can also be noticed in Table 1, rates of accident in Norway seem to be higher than in the rest of the countries considered.

Next, HazMat release probability estimates are examined, where uncertainties play an important role in this direction. There is a considerable variance in estimating these probabilities as reported by various researchers (Pet-Armacost et al.1999, Button and Reilly, 2000, Erkut and Verter, 1998, Saccomanno and Haastrup, 2002), because data are scarce and values depend on methodology and data sources used, as well as assumptions made. In this work, the analysis of the study by Button and Reilly (2000) is considered, where release probability estimates based on probability density functions were used as input variables for assessing the risk as given in equation (1) combined with equations (2) and (3). The expected release values are reported by HazMat type, load type and accident outcome and are used to calculate total incident rates for different incident scenarios. Table 2 shows the probability of incident outcomes given an accident for a truck carrying a flammable liquid (such as gasoline).

Moreover, we can assume that $50 \%$ of the shipments carry large loads, and 50\% carry small loads, which is quite consistent with a suggestion found in Hamouda (2004) for the case of Ontario. In 
Table 2. Release probabilities for flammable liquids (gasoline)

\begin{tabular}{|c|c|c|c|c|c|c|c|c|}
\hline $\begin{array}{c}\text { Accident } \\
\text { outcome }\end{array}$ & 0-c-II & 0-c-sl & 0-\| & 0-sl & c-II & c-sl & $\|$ & sl \\
\hline Large Spill & 0.3732 & 0.1621 & 0.3732 & 0.1622 & 0.0031 & 0.0013 & 0.0031 & 0.0014 \\
Small Spill & 0.1285 & 0.2073 & 0.0504 & 0.2055 & 0.0005 & 0.0017 & 0.0004 & 0.0017 \\
Large Leak & 0.0296 & 0.0176 & 0.0296 & 0.0176 & 0.0002 & 0.0001 & 0.0002 & 0.0001 \\
Small Leak & 0.0244 & 0.0905 & 0.0244 & 0.0905 & 0.0002 & 0.0007 & 0.0002 & 0.0008 \\
\hline
\end{tabular}

addition, we can consider the accident outcome probability estimates in the same study, in order to draw possible insights into the range within which these probabilities may vary. For the case of collision and overturn the probability of accident outcome is 0.016 , for collision only it is 0.843 , for overturn only it is 0.027 and if neither collision nor overturn occurs, the probability estimate is 0.115 .

${ }^{*}$ o-c-ll refers to the scenario when overturn, collision and a large load are involved. Analogously, o-c-sl refers to scenario with overturn, collision and small load, o-ll with overturn and large load, o-sl with overturn and small load, c-ll with collision only and large load, c-sl with collision only and small load, ll with no overturn and no collision, but large load, and sl with no overturn and no collision, but small load

Thus, if a probability release outcome needs to be even vaguely estimated, some indicative values can be considered in order to obtain more informed estimates. For instance, if the total gasoline large spill release probability rate needs to be calculated, the following equation can be used:

$\mathrm{P}($ gasoline, large spill $)=\mathrm{P}($ gasoline, large spill, $\mathrm{o}-\mathrm{c}-1 \mathrm{ll}) * \mathrm{P}(\mathrm{o}-\mathrm{c}){ }^{*} \mathrm{P}(\mathrm{ll})+\mathrm{P}($ gasoline large spill, o-ll $)$ * $\mathrm{P}(\mathrm{o}){ }^{*} \mathrm{P}(\mathrm{ll})+\mathrm{P}($ gasoline large spill, $\mathrm{c}-\mathrm{ll}){ }^{*} \mathrm{P}(\mathrm{c}){ }^{*} \mathrm{P}(1 \mathrm{l})$ $+\mathrm{P}($ gasoline large spill, $1 \mathrm{l}){ }^{*} \mathrm{P}($ no-nc $) * \mathrm{P}(1 \mathrm{l})+$ $\mathrm{P}$ (gasoline large spill, o-c-sl $) * \mathrm{P}(\mathrm{o}-\mathrm{c}) * \mathrm{P}(\mathrm{sl})+$ $\mathrm{P}($ gasoline large spill, o-sl $) * \mathrm{P}(\mathrm{o}){ }^{*} \mathrm{P}(\mathrm{sl})+$ $\mathrm{P}($ gasoline large spill, c-sl $) * \mathrm{P}(\mathrm{c}){ }^{*} \mathrm{P}(\mathrm{sl})+$ $\mathrm{P}($ gasoline large spill, sl $) * \mathrm{P}($ no-nc $){ }^{*} \mathrm{P}(\mathrm{sl})=0.0134$ where $\mathrm{P}($ no-nc) is the probability when no overturn and no collision happen.

It can be observed in Table 2, that when an overturn is involved the release probabilities are much higher compared to accidents where no overturns are involved. In the previous case, for example, the probability of a gasoline large spill release when no overturn occurs is 0.0021 .
Although the aforementioned estimates come from a couple of different databases containing records regarding truck accidents and incidents rates and have been analyzed based on probability functions (rather than point estimates), the present study still provides an analysis of the uncertainty involved using Monte Carlo simulation propagating the uncertainties to the outcomes leading to certain insights about the overall risk occurrence estimates and their impact on configuring the HazMat transportation network. In any case, the selection of the network has a direct impact on the risks in HazMat transportation. Thus, there is a need in incorporating all relevant and available risk-related information and historical data in determining the optimal transportation network configuration within an acceptable level of risk.

\section{Analysis Methods}

First, Monte Carlo Simulation was performed based on available data ranges discussed before, and using the XLSim ${ }^{\circledR}$ package for Excel (Savage, 2003). After examining the frequencies of HazMat release and risk incident probabilities, we turned our attention into the investigation of the impact of the aforementioned uncertainties on the minimum cost HazMat transportation network model.

\subsection{Monte Carlo Simulations for incident probabilities and risk per shipment}

Monte Carlo Simulation represents a powerful tool for an experiential understanding of risk and uncertainties involved in nearly all system models. In the present case, we first introduced the estimates of low, most likely and high values for the uncertain input variables of accident rates, using the triangular distribution function, which for different route types (urban or rural) was assigned different parameter values, based on the corresponding values presented in Table 1.

Next, towards the same lines, release probabilities on different road types are estimated based on data ranges described above, using the resampling function assuming that those probabilities may not follow an idealized distribution. After the re-sampling of data, Monte Carlo simulation was 
performed for release event probabilities expressed in equation (2), incorporating both uncertainties of accident and release rates. Finally, the consequence of a release event was estimated based on equation (3) assuming two different population densities, one for an urban (impact) area and a smaller for rural areas, as well as a reference value $(1 \mathrm{Km})$ for the radius of the impact area.

\subsection{Minimum Cost Transportation Network}

A network flow model represents a general transportation model in which material flows through it. The network is represented by nodes and arcs and transportation takes place from a supply source or origin node to a demand site or destination node, whereas intermediate nodes exist between them. Flows are allowed in either directions over the arcs. There are also capacity constraints on individual arcs within the network that limit the hourly or daily flows. The transportation flow model used here comprises of two sections: the one with the arc data and the other with the nodes flow balances to ensure that the total flow entering each node equals the total flow leaving the node (conservation constraints). After specifying the data in both sets, the flow network problem can be solved with the Excel Solver. The transportation flow network considered here is represented by the minimum cost problem, where the objective is to determine the maximum possible flow through the network solution at minimum cost. Total cost will be the summation product of flows through arcs and the corresponding costs for unit flow. In the present case, we also consider risk constraints imposed to ensure safety in the network.

\section{Analysis}

In the present work we consider an example transportation network with typical nodes and arcs as shown in Figure 1. Gasoline (a flammable liquid) needs to be transported from the origin (node 1) to a destination (node 6).

Data used in the particular network are shown in Table 3 and refer to the possible routes from leaving nodes to entering nodes, the corresponding type of each road (e.g. either urban or rural), maximum capacities for daily shipments, distances between nodes (in $\mathrm{Km}$ ), and unit cost (cost per flow unit, e.g. shipment) for each possible route. In addition, safety constraints are imposed in terms of a maximum risk value for each of the possible routes.

As described in the previous section (research methodology), accident rates and probability release incidents were calculated based on the specific functions of the data used and analyzed before, whereas risk per shipment was then simulated for each possible route. It was found that particularly

Figure 1. A sample transportation network with $1=$ origin and $6=$ destination

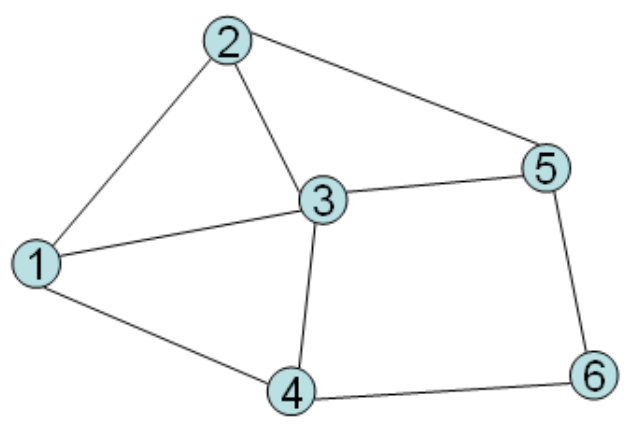

Table 3. Input variables and corresponding values

\begin{tabular}{|c|c|c|c|c|c|c|}
\hline $\begin{array}{c}\text { From } \\
\text { Node }\end{array}$ & $\begin{array}{c}\text { To } \\
\text { Node }\end{array}$ & $\begin{array}{c}\text { Road } \\
\text { type } \\
\left(\begin{array}{c}\text { U=urban, } \\
\text { R=rural) }\end{array}\right.\end{array}$ & $\begin{array}{c}\text { Capacity } \\
\text { (shipments/ } \\
\text { day) }\end{array}$ & $\begin{array}{c}\text { Distance } \\
(\text { Km) }\end{array}$ & $\begin{array}{c}\text { Cost/ } \\
\text { unit } \\
\text { (\$/shipm.) }\end{array}$ & $\begin{array}{c}\text { Total Maximum } \\
\left.\text { Risk }{ }^{*} 10^{-9}\right)\end{array}$ \\
\hline 1 & 2 & $\mathrm{U}$ & 3 & 13 & 18 & 0.1 \\
1 & 3 & $\mathrm{R}$ & 5 & 15 & 10 & 0.1 \\
1 & 4 & $\mathrm{R}$ & 4 & 10 & 10 & 0.1 \\
2 & 1 & $\mathrm{U}$ & 0 & 13 & 18 & 0.1 \\
2 & 3 & $\mathrm{R}$ & 5 & 2 & 16 & 0.1 \\
2 & 5 & $\mathrm{U}$ & 3 & 10 & 20 & 0.1 \\
3 & 1 & $\mathrm{R}$ & 0 & 15 & 10 & 0.1 \\
3 & 2 & $\mathrm{R}$ & 1 & 2 & 16 & 0.1 \\
3 & 4 & $\mathrm{R}$ & 3 & 2 & 12 & 0.1 \\
3 & 5 & $\mathrm{R}$ & 4 & 13 & 14 & 0.1 \\
4 & 1 & $\mathrm{R}$ & 0 & 10 & 10 & 0.1 \\
4 & 3 & $\mathrm{R}$ & 4 & 2 & 12 & 0.1 \\
4 & 6 & $\mathrm{R}$ & 6 & 15 & 16 & 0.1 \\
5 & 2 & $\mathrm{U}$ & 2 & 10 & 20 & 0.1 \\
5 & 3 & $\mathrm{R}$ & 3 & 13 & 14 & 0.1 \\
5 & 6 & $\mathrm{U}$ & 2 & 5 & 12 & 0.1 \\
6 & 4 & $\mathrm{R}$ & 0 & 15 & 16 & 0.1 \\
6 & 5 & $\mathrm{U}$ & 0 & 5 & 12 & 0.1 \\
\hline
\end{tabular}


important were the risk-per-shipment values for the first two arcs from 1 to 2 (1-2) and from 1 to 3 (1-3). As seen in Figure 2, in comparing the means, it is obvious that mean risk-per-shipment for route 1-2 is greater than the corresponding mean for route 1-3, which suggests that there is more risk for shipping material through route 1-2 than for 1-3. However, there is still a chance that route 1-3 has a higher expected risk-per-shipment value. In particular, there is a $10 \%$ chance for which route $1-3$ has a higher riskper-shipment expected value than route 1-2. In addition, if Monte Carlo simulation is performed also for the probability of release incidents as expressed in equation (2), there is a greater than $20 \%$ chance that release incident probabilities for route 1-3 are greater than release probabilities for route 1-2.

Thus, if we simply compare the means of the probability distributions, it seems that there is less risk for the particular transportation problem using route 1-3 than 1-2. If we compare the distributions from Monte Carlo simulation, most of the time (93\%) route 1-3 seems safer than 1-2. However, there is a probability of $10 \%$ where $1-3$ is riskier and a $20 \%$ where route 1-3 shows greater release incident rates than 12. It is interesting to note, that although route 1-2 has a higher mean accident rate (it is an urban road), route 1- 3 is expected to have higher release probabilities based on Monte Carlo simulation. In balancing these two probabilities, there is still a chance for 1-3 to be less safe than 1-2. Thus, combined uncertainties always need to be considered, since their impacts may result in a very significant uncertainty, which may be overlooked sometimes in the effort of assessing the risk of HazMat transportation.

Figure 2. Cumulative graphs for risk-per-shipment probability values for routes 1 to 2 (r12) and 1 to $3(r 13)$

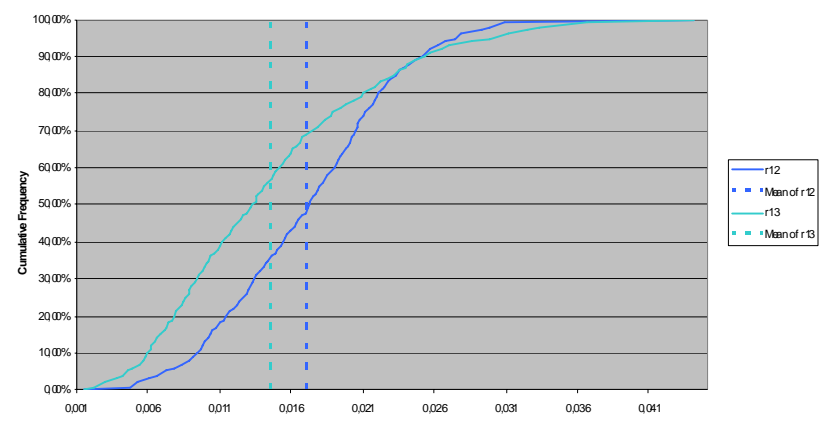

After the insights we obtained from Monte Carlo simulation, we attempt to solve the transportation network problem based on the $90 \%$ of the cases where route 1-3 seems to be safer than route 1-2 (or equally based on the $20 \%$ of the cases where release incident rates are higher on route 1-3). As expected, the network configuration for this case is shown in Fig. $3 a$, where we can see that shipments were deprived from using route 1-2. However, on the other side of the spectrum, there is still a $10 \%$ risk probability (or $20 \%$ release incident probability) where network configuration looks as in Fig.3b, for which shipments are allocated according to the specifications of the problem to all possible routes from supply point 1 (1-2, 1-3 and 1-4). Furthermore, the total cost of the network is different for the two cases; in the first case (Fig.3a) total transportation cost is \$214, whereas for the second case (Fig. $3 b$ ) total cost is $6.5 \%$ higher (\$228).

Tables 4 and 5 show the actual solutions to the transportation problem for the two different probabilities of risk in the HazMat transportation model we examine here. It is also evidence that solutions to network flow problems may vary a lot

Figure 3. Solutions to the transportation network problem for different risk incident probabilities

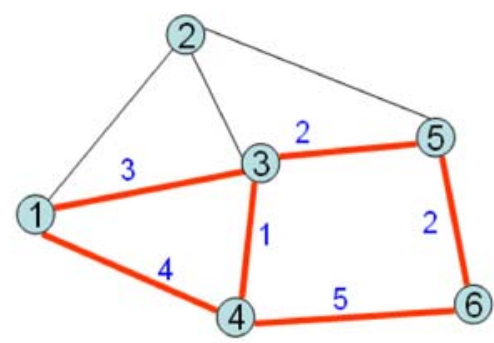

\section{a. Solution for $90 \%$ of incident rate cases}

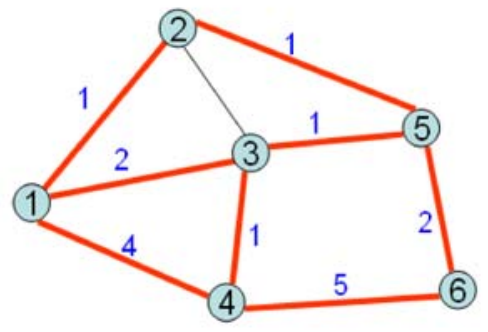

b. Solution for $10 \%$ of incident rate cases 
with acceptable risk levels, and may become infeasible if acceptable risk zones get more restricted.

Table 4. Solution to the transportation network corresponding to probability $90 \%$

Total Cost: $\$ 214$

Nodes Summary

\begin{tabular}{|c|c|c|c|c|c|c|}
\hline & To & To & To & To & To & To \\
\hline & 1 & 2 & 3 & 4 & 5 & 6 \\
\hline Source & 7 & & & & & \\
\hline To & 0 & 0 & 3 & 5 & 2 & 7 \\
\hline Total & 7 & 0 & 3 & 5 & 2 & 7 \\
\hline \multicolumn{7}{|c|}{$=======$ Leaving Nodes $=======$} \\
\hline & From & From & From & From & From & From \\
\hline & 1 & 2 & 3 & 4 & 5 & 6 \\
\hline Sink & & & & & & 7 \\
\hline From & 7 & 0 & 3 & 5 & 2 & 0 \\
\hline Total & 7 & 0 & 3 & 5 & 2 & 7 \\
\hline
\end{tabular}

Table 5. Solution to the transportation network corresponding to probability $10 \%$

Total Cost: $\$ 228$

Nodes Summary

$\begin{array}{lllllll}===== & \text { Entering } & \text { Nodes }====== & & \\ & \text { To } & \text { To } & \text { To } & \text { To } & \text { T0 } & \text { To } \\ & 1 & 2 & 3 & 4 & 5 & 6 \\ \text { Source } & 7 & & & & & \\ \text { To } & 0 & 1 & 2 & 5 & 2 & 7 \\ \text { Total } & 7 & 1 & 2 & 5 & 2 & 7\end{array}$

$\begin{array}{lllllll}======\text { Leaving } & \text { Nodes }====== & & & \\ & \text { From } & \text { From } & \text { From } & \text { From } & \text { From } & \text { From } \\ & 1 & 2 & 3 & 4 & 5 & 6 \\ \text { Sink } & & & & & & 7 \\ \text { From } & 7 & 1 & 2 & 5 & 2 & 0 \\ \text { Total } & 7 & 1 & 2 & 5 & 2 & 7\end{array}$

\section{Conclusions}

The present study addresses the HazMat transportation problem by means of initially evaluating certain pertinent features that have proven to be very case-dependent for each transportation system and highly sensitive to a number of irreducible uncertainties associated with key input variables, as well as in the probabilities of risk occurrences. In trying to analyze the available data, Monte Carlo simulations were conducted to estimate release event probabilities incorporating both uncertainties associated with accident and release rates. In addition, potential consequences of release events were assessed by assuming two different population densities, whereas resulting outcomes for risk per shipment probabilities were obtained by propagating input uncertainties though the underlying risk model. Finally, the impact of the uncertainties on the transportation network configuration was observed. The results showed that although the mean risk per shipment value for a specific path (1-2) may be higher than the corresponding value of another path (1-3), there is still a risk zone in which the second route (1-3) is less safe for a given tolerable risk level. Furthermore, the transportation network may become significantly different in cases where risk levels become more stringent. Consequently, uncertainties need to be always taken into account when estimating risk incident rates in the areas of transportation security and safety, designing comprehensive risk assessment and management frameworks, informing regulatory policy development as well as designing wellfunctioning and cost-efficient transportation networks in the presence of increasing awareness of the attendant risks to public health and the environment.

\section{Acknowledgement}

The authors would like to thank Prof. Triantafyllou and Prof. Folina at the Department of Logistatics, ATEI of Thessaloniki, for their kind invitation to participate in the special issue of the Operation and Supply Chain Management (OSCM) Journal.

Financial support provided by the National Science Foundation through grant CBET-1008158 is gratefully acknowledged by Nikolaos Kazantzis.

\section{References}

Barnhart C., and G. Laporte (2007), Handbooks in Operations Research and Management Science, Transportation, 14, North Holland, Amsterdam, The Netherlands

Button N.P., and P.M. Reilly (2000), Uncertainty in incident rates for trucks carrying dangerous goods, Accident Analysis and Prevention 32, pp. 797-804 
Clark R.M., and M.E. Besterfield-Sacre (2009), A new approach to hazardous materials transportation risk analysis: decision modeling to identify critical variables, Risk Analysis 29, pp.344-354

Directorate General XVI, Country Report, Greece, Thematic Study of Transport (2000), Operational Programs for Transport (OPT)

Erkut E., and F. Gzara (2008), Solving the hazmat transport network design problem, Computers and Operations Research 35, pp.2234-2247

Erkut E, and A. Ingolfsson (2005), Transport risk models for hazardous materials: revisited, Operations Research Letters 33, pp.81-89.

Erkut, E. and V. Verter (1998), Modeling of transport risk for hazardous materials, Operations Research 46, pp.625-642

Glickman T. S., and M.A. Sontag MA. (1995), The tradeoffs associated with rerouting highway shipments of hazardous materials to minimize risk, Risk Analysis 15, pp.61-67

Hamouda, G.M. (2004), Risk-based decision support model for planning emergency response for hazardous materials road accidents, PhD thesis, Civil Engineering Department, University of Waterloo, Ontario, Canada

Harwood, D.W., J.G. Viner, and E.R. Russell (1993), Procedure for developing truck accident and release rates for hazmat routing, Journal of Transportation Engineering 119, pp.189-199

Kara B.Y., and V. Verter (2004), Designing a road network for hazardous materials transportation, Transportation Science 38, pp.188-196

List, G.F., P.B. Mirchandani, M. Turnquist and K.G. Zografos (1991), Modeling and analysis of hazardous materials transportation: risk analysis, routing/scheduling and facility location, Transportation Science 25, pp. 100-114
McCord, M.R. and A.Y.C. Leu (1995), Sensitivity of optimal hazmat routes to limited preference specification, Information Systems and Operational Research 33, pp. 6883

Pet-Armacost, J.J., J. Sepulveda and M. Sakude (1999), Monte Carlo sensitivity analysis of unknown parameters in hazardous materials transportation risk assessment, Risk Analysis, 19, pp.1173-1184

Qiao Y., M. Gentile, and M.S. Mannan (2005), Fuzzy logic methodology for accident frequency assessment in hazardous materials transportation, in Center for Chemical Process Safety - 19th Annual International Conference: Emergency Planning, Preparedness Prevention and Response, John Wiley \& Sons, Inc., Hoboken, NJ, pp. 215-224

ReVelle, C.J., J. Cohon, and D. Shobrys (1991), Simultaneous siting and routing in the disposal of hazardous wastes, Transportation Science 25, pp.138-145

Saccomanno, F. F. and P. Haastrup (2002), Risk-based decision support model for planning emergency response for Hazardous Materials road accidents, Risk Analysis 22, pp.1059-1069

Savage, S. (2003), Decision Making with Insight, Thomson Learning, Inc., Brooks/Cole

U.S. Department of Transport (1989), Guidelines for applying criteria to designate routes for transporting hazardous materials, Report No. DOT/RSPA/OHMT- 89-02, Federal Highway Administration, Washington, DC

Ziliaskopoulos A.K. and W. Wardell (2000), An intermodal optimum path algorithm for multimodal networks with dynamic arc travel times and switching delays, European Journal of Operational Research, 125, pp.486-502

Zografos K.G. and K.N. Androutsopoulos (2008), A decision support system for integrated hazardous materials routing and emergency response decisions, Transportation Research Part C 16, pp.684-703

Vasiliki Kazantzi is an Assistant Professor at the Department of Project Management in the Technological Institute of Larissa, Greece. She received her Ph.D. in Chemical Engineering from Texas A\&M University, College Station, TX, USA. She has a Master of Engineering from Texas A\&M University and a Bachelor of Science from University of Thessaloniki, Greece, both in chemical engineering. Dr. Kazantzi worked on several projects in the USA sponsored by federal and state agencies, as well as by the industry. Her research interests lie in the broader areas of Operations Management (Operations Design, Planning and Optimization, Sustainable Operations Management, Safety and Control), and Productive Process Systems Analysis and Integration. She is a member of the American Institute of Chemical Engineers (AIChE), the Greek Institute of Chemical Engineers and the Society of Women Engineers (SWE).

Nikolaos Kazantzis was educated at the Aristotle University of Thessaloniki (Greece), University of Cambridge (UK) and University of Michigan (USA) where he obtained his PhD in Chemical Engineering. Currently he is a Professor of Chemical Engineering at Worcester Polytechnic Institute (WPI), Worcester, Massachusetts, USA, an Associate Researcher at the Electricity Policy Research Group, Cambridge University, Cambridge, UK, as well as a member of the Technical Advisory Committee of the MKOC Process Safety Center, Texas A\&M University, College Station, Texas. Professor Kazantzis serves on the Editorial Boards of the IEEE Transactions on Control Systems Technology, Systems and Control Letters, European 
Journal of Control, IEEE Control Systems Society Conference, and is a member of the Technical Committee of Nonlinear Control Systems, International Federation of Automatic Control (IFAC). He is the recipient of the Career Award of the US National Science Foundation (NSF) and his research interests lie in the areas of systems analysis, monitoring, and control in the presence of complexity, process safety and chemical risk assessment, energy and environmental policy analysis.

Dr. Vassilis C. Gerogiannis holds a Diploma in Computer Engineering and a PhD in Software Engineering from the University of Patras, Greece. At present, Dr. Gerogiannis is an Assistant Professor for "Project Management Information Systems" at the Department of Project Management in the Technological Education Institute (TEI) of Larissa, Greece. He is also a Module Leader in a Postgraduate Program in Management Science organized by TEI in cooperation with the Staffordshire University, UK and a Lecturer at the Greek Open University, teaching the Software Engineering course. In the recent past, he was a visiting Lecturer at the University of Thessaly and at the Aristotle University of Thessaloniki, Greece. Up to now, he has published a number of papers in international journals and conference proceedings and he has participated as a project manager in EU funded R\&D (software development) projects. His research interests include Project Management, Process Assessment/Improvement and Simulation Techniques. 